Gut, 1971, 12, 819-821

\title{
Aspirin and alcohol in gastrointestinal haemorrhage
}

\author{
C. D. NEEDHAM, J. KYLE, P. F. JONES, S. J. JOHNSTON, AND \\ D. F. KERRIDGE
}

From the Gastroenterological Unit, Royal Infirmary, Aberdeen, and Department of Statistics, University of Aberdeen, Scotland

SUMMARY The intake of aspirin, of alcohol, and of a combination of both, among 817 patients admitted for gastrointestinal haemorrhage is reported. The incidence of ingestion in six diagnostic groups is compared with that in two control groups. Analysis confirms that there is a markedly significant association between overt haemorrhage and the ingestion of aspirin, but this was not shown for alcohol taken alone: the combination of aspirin and alcohol showed a highly significant synergistic effect.

The place of aspirin and of alcohol in the causation of major alimentary bleeding remains undecided. Langman (1970) summarized the position in a recent review and emphasized the need for further epidemiological studies with proper controls. The purpose of this paper is to present such a study.

\section{Methods}

During $1967 / 68817$ patients were admitted to the Aberdeen General Hospitals on account of haematemesis and/or melaena. The cause of the bleeding in these patients fell into six groups: duodenal ulcer 434, gastric ulcer 77 (duodenal ulcer also present in 13), gastritis/erosions 55, hiatal hernia 66, miscellaneous 144 , and source unknown 41. Each patient was questioned soon after admission by one of the authors (usually S.J.J.) about the ingestion of aspirin and of alcohol, with particular reference to the 72 hours before the onset of bleeding. Patients who initially denied taking 'aspirin' were given the names of many proprietary products before a negative reply was accepted. Enquiry was made into the reason for taking the drug.

During 1968 a control series of 300 inpatients were questioned similarly about aspirin intake within 72 hours of their admission to hospital (control group I). One hundred and thirteen of these were also asked about alcoholic intake within 72 hours of admission (control group II). All these patients, whose ages were similar to those in the survey, were in acute general medical and surgical Received for publication 3 August 1971. wards. It was decided to exclude from the control series those with rheumatic disorders and those whose memory appeared to be unreliable.

\section{Results}

The reasons given by patients for taking aspirin are given in Table I. There was no evidence that aspirin had been taken to relieve symptoms after the onset of bleeding.

\begin{tabular}{lcc}
\hline Reason for Taking Aspirin & Number & Percentage \\
\hline Stomach pains & 27 & 13 \\
Other pains & 85 & 42 \\
Infections & 25 & 12 \\
Hangover & 8 & 4 \\
Worry, tension, insomnia & 17 & 8 \\
Attempted suicide & 2 & 1 \\
Other & 6 & 3 \\
Unknown & 35 & 17 \\
& 205 & 100 \\
\hline
\end{tabular}

Table I Reasons given for taking aspirin

The incidence in the six diagnostic groups of ingestion of aspirin, of alcohol, and of both together within 72 hours of bleeding is given in Table II, and comparisons made with ingestion within 72 hours of admission in the two control groups.

\section{Statistical Analysis}

In the survey group of 817 patients, $17 \%$ of the men and $6.5 \%$ of the women had taken alcohol before 


\begin{tabular}{|c|c|c|c|c|c|}
\hline Diagnosis & Sex & Aspirin & Alcohol & $\begin{array}{l}\text { Both Aspirin } \\
\text { and Alcohol }\end{array}$ & $\begin{array}{l}\text { Total } \\
\text { No. }\end{array}$ \\
\hline $\begin{array}{l}\text { Duodenal } \\
\text { ulcer } \\
\text { Gastric } \\
\text { ulcer } \\
\text { Gastritis }\end{array}$ & $\begin{array}{l}\mathbf{M} \\
\mathbf{F} \\
\mathbf{M} \\
\mathbf{F} \\
\mathbf{M} \\
\mathbf{F}\end{array}$ & $\begin{array}{l}91(27 \%) \\
26(28 \%) \\
13(30 \%) \\
10(29 \%) \\
21(54 \%) \\
15(79 \%)\end{array}$ & $\begin{array}{c}50(15 \%) \\
7(8 \%) \\
7(16 \%) \\
4(12 \%) \\
18(50 \%) \\
2(11 \%)^{1}\end{array}$ & $\begin{aligned} 22 & (7 \%) \\
4 & (4 \%) \\
3 & (7 \%) \\
3 & (9 \%) \\
8 & (22 \%) \\
1 & (5 \%)^{1}\end{aligned}$ & $\begin{array}{r}342 \\
92 \\
43 \\
34 \\
36 \\
19\end{array}$ \\
\hline $\begin{array}{l}\text { Hiatal } \\
\text { hernia } \\
\text { Miscellaneous }\end{array}$ & $\begin{array}{l}\mathbf{M} \\
\mathbf{F}\end{array}$ & $\begin{array}{l}9(31 \%) \\
5(14 \%)\end{array}$ & $\begin{array}{l}3(10 \%) \\
1(3 \%)\end{array}$ & $\begin{array}{ll}2 & (7 \%) \\
0 & (0 \%)\end{array}$ & $\begin{array}{l}29 \\
37\end{array}$ \\
\hline $\begin{array}{l}\text { Varices } \\
\text { Others }\end{array}$ & $\begin{array}{l}\mathbf{M} \\
\mathbf{F} \\
\mathbf{M}\end{array}$ & $\begin{array}{l}0(0 \%) \\
1(13 \%)^{1} \\
7(10 \%)\end{array}$ & $\begin{array}{c}10(59 \%)^{1} \\
2(25 \%)^{1} \\
5(7 \%)\end{array}$ & $\begin{array}{ll}0 & (0 \%) \\
0 & (0 \%) \\
0 & (0 \%)\end{array}$ & $\begin{array}{r}17 \\
8 \\
70\end{array}$ \\
\hline $\begin{array}{l}\text { Source } \\
\text { unknown }\end{array}$ & $\begin{array}{l}\mathbf{F} \\
\mathbf{M} \\
\mathbf{F}\end{array}$ & $\begin{array}{l}4(8 \%) \\
2(10 \%)^{1} \\
1(5 \%)^{1}\end{array}$ & $\begin{array}{l}0(0 \%) \\
2(10 \%)^{1} \\
1(5 \%)^{1}\end{array}$ & $\begin{array}{ll}0 & (0 \%) \\
1 & (5 \%)^{1} \\
0 & (0 \%)\end{array}$ & $\begin{array}{l}49 \\
19 \\
22\end{array}$ \\
\hline Control I & $\begin{array}{l}\mathbf{M} \\
\mathbf{F}\end{array}$ & $\begin{array}{l}12(9 \%) \\
20(12 \%)\end{array}$ & ニ- & - - & $\begin{array}{l}130 \\
170\end{array}$ \\
\hline Control II & $\begin{array}{l}\mathbf{M} \\
\mathbf{F}\end{array}$ & $\begin{array}{l}3(6 \%) \\
8(14 \%)\end{array}$ & $\begin{array}{r}13(24 \%) \\
2(3 \%)\end{array}$ & $\begin{array}{ll}1 & (2 \%) \\
1 & (2 \%)\end{array}$ & $\begin{array}{l}54 \\
59\end{array}$ \\
\hline
\end{tabular}

Table II Incidence of taking aspirin and alcohol within 72 hours of hospital admission for gastrointestinal bleeding in the six main diagnostic groups, with controls, in Aberdeen in 1967-68

${ }^{1}$ These percentages are based on small total numbers.

admission. The corresponding figures for the control group II were $24 \%$ and $3 \%$; this does not provide evidence that alcohol increases the risk of bleeding. In the separate diagnostic groups, only patients with gastritis and oesophageal varices show an excess incidence of taking alcohol. In these two groups, an excess is to be expected because the diagnosis of gastritis depended in part on a history of alcohol ingestion, and the possible association of oesophageal varices with alcohol is well known. In these groups the appearance of an excess, in accordance with expectation, helps to establish the validity of the control group.

Twenty-six per cent of the men and $24 \%$ of the women in the survey group had taken aspirin, as compared with $9 \%$ of men and $12 \%$ of women in control group I, or $6 \%$ of men and $14 \%$ of women in control group II. These substantial differences clearly support previous investigations and establish that there is a case to be examined in greater detail by statistical means. All the significance tests which follow have been done by the usual procedure which standardizes for sex differences (Armitage, 1971). This removes any possibility of bias due to unequal sex ratios, without testing the males and females separately which would lead to very small numbers.

When all diagnostic categories are taken together, the differences from the proportions taking aspirin in control group $I$ is highly significant $\left(\chi_{1}{ }^{2}=24 \cdot 4\right.$, $P<0.001$ ). For the separate diagnostic categories, the results are summarized in Table III. The association between bleeding and aspirin is highly significant in the peptic groups, but not in the 'source

\begin{tabular}{lll}
\hline Diagnosis & \multicolumn{2}{c}{ Aspirin v. Control } \\
\cline { 2 - 3 } & $\chi_{1}{ }^{2}$ & $\begin{array}{l}\text { Significance } \\
\text { Level (\%) }\end{array}$ \\
\hline All diagnoses & $24 \cdot 4$ & $0 \cdot 1$ \\
Duodenal ulcer & $24 \cdot 2$ & $0 \cdot 1$ \\
Gastric ulcer & $18 \cdot 2$ & $0 \cdot 1$ \\
Gastritis & $88 \cdot 4$ & $0 \cdot 1$ \\
Hiatal hernia & $5 \cdot 5$ & $5 \cdot 0$ \\
Varices & $0 \cdot 9$ & n.s. \\
Other non-peptic & $0 \cdot 1$ & n.s. \\
Source unknown & $0 \cdot 4$ & n.s. \\
\hline
\end{tabular}

Table III Significance tests on patients taking aspirin against controls

unknown' and the other non-peptic groups. That the significance in the peptic groups is not due to biased recording of diagnostic group is guaranteed by the fact that the difference is highly significant when all diagnostic categories are taken together. The absence of an effect in the non-peptic groups, particularly the oesophageal varices, is further confirmation of the validity of the control group.

It is possible that the higher incidence of aspirin taking among the patients with bleeding is a reflection of greater pain felt by those about to bleed. However, among the 612 patients admitted who had not taken aspirin, $46 \%$ had been free of pain immediately before bleeding commenced; $43 \%$ of the 205 patients who had taken aspirin had likewise been pain-free. The difference between these groups is not statistically significant. Furthermore only $13 \%$ of those who had ingested aspirin before admission stated that they had done so to relieve abdominal pain (Table I).

The next step is to establish whether the effect of aspirin in combination with alcohol is worse than the sum of the separate effects, ie, whether a synergistic effect takes place. If all the patients who bled are taken together, standardizing for sex, the following contingency table can be constructed (expected numbers in brackets, calculated on the assumption of simply additive effects):

\begin{tabular}{lcll}
\hline & Alcohol & No Alcohol & \\
\hline Aspirin & $44(28.1)$ & $161(176.9)$ & 205 \\
No aspirin & $68(83.9)$ & $544(528 \cdot 1)$ & 612 \\
& 112 & 705 & 817 \\
& $x^{2}=13.9, \mathrm{P}<0.001$ & & \\
\hline
\end{tabular}

This result is highly significant. It can be confirmed that no bias exists (eg, aspirin taking being commonly the result of alcohol drinking) by testing the control group in the same way: here the result is not significant $\left(\chi^{2}=0.2, \quad P>0.5\right)$. Of the separate diagnostic groups, only the duodenal ulcer group 
shows'a high level of significance. The numbers in some of the other groups are small when subdivided by aspirin and alcohol, but real differences may exist, especially in the gastric ulcer and gastritis groups. In the non-peptic groups, however, there is no suggestion of any effect. This strengthens the evidence for a real aspirin/alcohol association in the duodenal ulcer group, since any bias in recording ought to apply to all groups equally.

\section{Discussion}

This series agrees with others (Brown and Mitchell, 1956; Alvarez and Summerskill, 1958; Muir and Cossar, 1959; Parry and Wood, 1967) in finding greater aspirin ingestion in patients with gastrointestinal haemorrhage than in control subjects. In the four earlier series the patients' aspirin intake in the 48 hours before admission was studied; in the present series the longer period of 72 hours was taken. Nevertheless, the percentages of controls and of patients who had taken aspirin were only $10 \%$ and $25 \%$ respectively in North East Scotland compared with the $11-26 \%$ for controls and $51-58 \%$ for patients reported by the earlier workers. The reason for the difference between the series is not known, but the present series is considered to be accurate for its defined population and geographical region.

Alcohol taken by itself does not, on the evidence of this study, increase the risk of bleeding - a conclusion which is in agreement with the experimental findings in seven normal men (Goulston and Cooke, 1968).

The combination of aspirin and alcohol has been considered as being likely to cause alimentary bleeding (Lancet, 1970). Goulston and Cooke (1968) showed that in 13 normal men, seven Disprin tablets taken with $180 \mathrm{ml}$ of undiluted whisky on each of three successive days produced a greater increase in faecal occult blood loss than when the same dose of aspirin preparation alone was taken. Earlier investigations of patients with frank bleeding who had taken both aspirin and alcohol gave inconclusive results (Langman, 1970): the present study provides evidence of a definite synergistic effect.

Ingestion of alcohol or aspirin alone is so widespread that only a very small proportion of the population at risk can suffer overt haemorrhage. Unfortunately there is no known way to identify those who are susceptible. To take aspirin and alcohol together is a much less common practice but the risk of precipitating bleeding is a real one. There seems to be a good case for warning the public of the dangers of this combination.

We thank all our medical and surgical colleagues who gave us free access to the patients under their care. Professor R. Deans Weir, of the Department of Social Medicine, gave valuable advice during the planning of this survey, which was financed by a grant from the North Eastern Regional Hospital Board (Scotland). We are deeply indebted to our secretary, Mrs C. Smith, for her assistance in processing the data.

\section{References}

Alvarez, A. S., and Summerskill, W. H. J. (1958). Gastrointestinal haemorrhage and salicylates. Lancet, 2, 920-925.

Armitage, P. (1971). Statistical Methods in Medical Research. Blackwell, Oxford.

Brown, R. K., and Mitchell, N. (1956). The influence of some of the salicyl compounds (and alcoholic beverages) on the natural history of peptic ulcer. Gastroenterology, 31, 198-203.

Goulston, K., and Cooke, A. R. (1968). Alcohol, aspirin and gastrointestinal bleeding. Brit. med. J., 4, 664-665.

Langman, M. J. S. (1970). Epidemiological evidence for the association of aspirin and acute gastrointestinal bleeding. Gut, 11, 627-634.

Lancet (1970). Gastrointestinal bleeding: what progress? (Editorial). Lancet, 1,1157-1158.

Muir, A., and Cossar, I. A. (1959). Aspirin and gastric haemorrhage. Lancet, 1, 539-541.

Parry, D. J., and Wood, P. H. N. (1967). Relationship between aspirin taking and gastroduodenal haemorrbage. Gut, 8, 301-307. 